Original Article

\title{
ASSESSMENT OF CARDIOVASCULAR RISK AND COMORBIDITY IN PATIENTS WITH CHRONIC KIDNEY DISEASE
}

\author{
Slobodan Davinic' ${ }^{1}$ Ivana Davinic ${ }^{2}$, Ivan Tasic ${ }^{2,3}$ \\ ${ }^{I}$ Department of Nephrology Dialysis Centre, General Hospital Leskovac, Serbia \\ ${ }^{2}$ Faculty of Medicine, Nis, Serbia \\ ${ }^{3}$ Institute for Cardiology and Rheumatology Niška Banja, Serbia
}

\begin{abstract}
High rates of morbidity and mortality in patients with chronic diseases of the kidney are for the most part caused by the high prevalence of cardiovascular diseases and high rates of fatal cardiovascular events. The aim of the study was to establish the prevalence and distribution of cardiovascular risk factors in patients with chronic kidney diseases, in various stages of chronic renal failure. The examinees were classified into three groups based on the level of glomerular filtration rate: over $60 \mathrm{ml} / \mathrm{min} / 1.73 \mathrm{~m}^{2}$; $30-59 \mathrm{ml} / \mathrm{min} / 1.73 \mathrm{~m}^{2}$; and $15-29 \mathrm{ml} \mathrm{min} / 1.73 \mathrm{~m}^{2}$. Traditional risk factors of age, hypertension, systolic blood pressure, glycemia, diabetes, serum level of total cholesterol and triglycerides, triglyceridemia, and hypertrophy of the left ventricle showed a significantly positive rising trend of their mean values or prevalence, inversely dependent upon the level of declining glomerular filtration rates. Mean values of serum HDL cholesterol level demonstrated a significant declining trend, concomitant with decreasing glomerular filtration rate. The prevalence of hypercholesterolemy, smoking and obesity, as well as the mean value of body mass index, showed significant intergroup variations, but without any continuing trend related to glomerular filtration rate. Non-traditional risk factors of anemia, proteinuria, and hypoalbuminemia showed a significant rising trend of prevalence inversely dependent upon the degree of reduction of glomerular filtration rate. The levels of hematocrit and serum albumins showed a positive correlation with the reduction of glomerular filtration rate. In pre-dialysis patients with chronic kidney diseases, a high prevalence of the studied cardiovascular risk factors was found. Cardiovascular risk progressively rises with decreasing glomerular filtration rate, being significantly elevated as early as the initial stages of renal failure.
\end{abstract}

Key words: chronic kidney disease, cardiovascular risk, cardiovascular morbidity.

\section{Introduction}

Chronic kidney disease (CKD) patients are patients with high morbidity and mortality rates. The high mortality rate is for the most part caused by high prevalence of cardiovascular diseases and high rates of fatal cardiovascular events in CKD patients. Individuals with CKDs are at a higher risk of dying of cardiovascular diseases thanof developing terminal kidney failure [1,2].

CKD patients have a three times higher incidence of classical, i.e. traditional cardiovascular risk factors compared to the general population. Moreover, "non-traditional" cardiovascular risk factors and specific changes in CKDs are considerably involved in the pathogenesis of cardiovascular diseases in chronic uremia: hypervolemia and renin-angiotensin-aldosteron system activation, hyperhomocysteinemia, oxidative stress, chronic inflammation

Correspondence to: Slobodan Davinić, M.D., MSc

Dept. of Nephrology Dialysis Centre, General Hospital Leskovac

9 Rade Končara, 16000 Leskovac, Serbia

Phone: +381638131747

E-mail: sdavinic@ptt.rs

Received January $31^{\text {st }}, 2017$, accepted for publication December $11^{\text {th }}, 2017$ and malnutrition (MIA syndrome), secondary hyperparathyroidism and abnormal metabolism of calcium and phosphorus, disturbed acid-base balance, anemia, thrombotic system alteration, direct effects of uremic toxins $[3,4]$.

\section{Aim of the Study}

The aim of the study was to establish the prevalence and distribution of cardiovascular risk factors in CKD patients in different stages of chronic renal failure.

\section{Method}

The study involved 205 CKD patients in the pre-dialysis stage, aged 55.1 \pm 4.9 years, at the Department of Nephrology with Dialysis Center, General Hospital Leskovac (Table 1).

The examinees were divided into three groups based on the level of their renal function, i.e. their glomerular filtration rate (GFR): 
Table 1 basic patient characteristics

\begin{tabular}{|c|c|c|c|c|}
\hline & $\begin{array}{c}\text { Total number of } \\
\text { examinees } \\
205 \\
\end{array}$ & $\begin{array}{c}>60 \\
\mathrm{ml} / \mathrm{min} \\
60 / 29.3 \%\end{array}$ & $\begin{array}{c}30-59 \\
\mathrm{ml} / \mathrm{min} \\
86 / 42.0 \%\end{array}$ & $\begin{array}{c}15-29 \\
\mathrm{ml} / \mathrm{min} \\
59 / 28.8 \%\end{array}$ \\
\hline Age (in years) & $55.1 \pm 4,9$ & $52.3 \pm 7,7$ & $59.7 \pm 8,9$ & $63.0 \pm 4.5$ \\
\hline$<45$ & $19.5 \%(40 / 205)$ & $23.3 \%(14 / 60)$ & $19.8 \%(17 / 86)$ & $15.3 \% \quad(9 / 59)$ \\
\hline $45-65$ & $42.0 \%(86 / 205)$ & $33.3 \%(20 / 60)$ & $43.0 \%(37 / 86)$ & $40.2 \% \quad(29 / 59)$ \\
\hline$>65$ & $38.5 \%(79 / 205)$ & $43.3 \%(26 / 60)$ & $37.2 \%(32 / 86)$ & $35.6 \%(21 / 59)$ \\
\hline \multicolumn{5}{|l|}{ Gender } \\
\hline men & $48.8 \%(100 / 205)$ & $51.7 \%(31 / 60)$ & $47.7 \%(41 / 86)$ & $47.5 \% \quad(28 / 59)$ \\
\hline women & $51.2 \%(105 / 205)$ & $48.3 \%(29 / 60)$ & $52.3 \%(45 / 86)$ & $52.5 \%(31 / 59)$ \\
\hline $\operatorname{BMI}\left(\mathrm{kg} / \mathrm{m}^{2}\right)$ & $28.0 \pm 4.5$ & $26.8 \pm 3.8$ & $29.4 \pm 4.2$ & $28.6 \pm 4.4$ \\
\hline \multicolumn{5}{|l|}{ Kidney disease } \\
\hline glomerulo(pyelo)nephritis & $15.6 \%(32 / 205)$ & $8.3 \% \quad(5 / 60)$ & $19.8 \%(17 / 86)$ & $16.9 \%(10 / 59)$ \\
\hline nephro(angio)sclerosis & $11.2 \%(23 / 205)$ & $18.3 \%(11 / 60)$ & $8.1 \% \quad(7 / 86)$ & $8.5 \%(5 / 59 /)$ \\
\hline diabetic nephropathy & $19.0 \%(39 / 205)$ & $23.3 \%(14 / 60)$ & $18.6 \%(16 / 86)$ & $15.3 \% \quad(9 / 59)$ \\
\hline policystic kidney disease & $6.8 \%(14 / 205)$ & $11.7 \% \quad(7 / 60)$ & $4.7 \% \quad(4 / 86)$ & $5.1 \% \quad(3 / 59)$ \\
\hline endemic nephropathy & $4.4 \% \quad(9 / 205)$ & $8.3 \% \quad(5 / 60)$ & $2.3 \% \quad(2 / 86)$ & $3.4 \% \quad(2 / 59)$ \\
\hline urologic disease & $12.7 \%(26 / 205)$ & $20.0 \%(12 / 60)$ & $12.8 \%(11 / 86)$ & $5.1 \% \quad(3 / 59)$ \\
\hline other/unknown & $30.2 \%(62 / 205)$ & $16.7 \%(10 / 60)$ & $33.7 \%(29 / 86)$ & $39.0 \%(23 / 59)$ \\
\hline
\end{tabular}

BMI - body mass index

1. slightly reduced GFR (over $60 \mathrm{ml} / \mathrm{min} / 1.73 \mathrm{~m}^{2}$ ) 60 examinees - group A;

2. moderately reduced GFR (30-59 $\left.\mathrm{ml} / \mathrm{min} / 1.73 \mathrm{~m}^{2}\right)$ 86 examinees - group B;

3. significantly reduced GFR $\left(15-29 \mathrm{ml} / \mathrm{min} / 1.73 \mathrm{~m}^{2}\right)$ 59 examinees - group $\mathrm{C}$.

The prevalence of complications and comorbid conditions in chronic renal failure start to grow with GFR reduced below $60 \mathrm{ml} / \mathrm{min} / 1.73 \mathrm{~m}^{2}$, so that most researchers, studies, and clinical guidelines tend to consider this value as the point of onset of hronic renal failure. The group of examinees with GFR of $60 \mathrm{ml} / \mathrm{min} / 1.73 \mathrm{~m}^{2}$ and higher was taken as the reference group in further analyses and comparisons [5-8].

Due to the fact that the MDRD equation and CockroftGault formula have got numerous limitations, especially when cardiovascular patients are concerned, GFR was determined in this study via the mean values of creatinin clearance in at least two samples of $24 \mathrm{~h}$ urine creatinine excreation and serum creatinine. The same $24 \mathrm{~h}$ urine was also used for proteinuria measurements.

The following variables were considered the traditional cardiovascular risk factors: male gender, elevated blood pressure, obesity, diabetes, hypercholesterolemia, low HDL cholesterol, hypertriglyceridemia, left ventricular hypertrophy (LVH), smoking, as well as age, systolic and diastolic blood pressure values and body mass index (BMI). Hypertension was defined as the values of systolic pressure $\geq 140 \mathrm{mmHg}$ and diastolic pressure $\geq 90 \mathrm{mmHg}$ or the use of antihypertensive agents. Hypercholesterolemia was defined as the serum fasting cholesterol $\geq 6.5 \mathrm{mmol} / \mathrm{l}$, $\geq 5.0 \mathrm{mmol} / \mathrm{l}$ in the cases of an earlier myocardial infarction or the patient using antilipemic drugs. Left ventricular hypertrophy was defined, based on the echocardiographic test, as a thickness of the posterior left ventricle wall of over $11 \mathrm{~mm}$, and/or interventricular septal thickness of over $12 \mathrm{~mm}$. The criterion for diabetes was fasting serum glucose $\geq 7.0 \mathrm{mmol} / \mathrm{l}$, serum glucose without fasting, postprandial, $\geq 11.1 \mathrm{mmol} / \mathrm{l}$, or the use of oral antidiabetic agents. Obesity was defined as the body mass index (BMI) $>30 \mathrm{~kg} / \mathrm{m}^{2}$. BMI was calculated as the ratio of body weight (in $\mathrm{kg}$ ) and body surface (in $\mathrm{m}^{2}$ ) calculated from nomogram tables via body height. Smoking status was defined as active smoker or the period of smoking of less than a year before the onset of the study.

Among the non-traditional cardiovascular risk factors we included proteinuria, anemia, and hypoalbuminemia, as well as the mean values of hematocrit, leukocytes in the blood, serum albumin and fibrinogen.

Cox logistic regression was used to examine the association of cardiovascular risk factors with glomerular filtration rates. Chi-square and Wilcoxon tests were used to establish the prevalence and distribution of variables.

\section{Results}

The values were presented as absolute in the form of mean values with standard deviation or in percentage form, i.e. the prevalence of cardiovascular risk factors. The data were presented for the total number of patients and by groups A, $\mathrm{B}$, and $\mathrm{C}$, based on the level of renal function.

Table 2 presents the data for traditional cardiovascular risk factors.

The following variables showed a significant positive rising trend of mean values or prevalence, inversely dependent upon the degree of decrease of GFR values: age, hypertension, systolic blood pressure, glycemia, diabetes, serum levels of total cholesterol and triglycerides, triglyceridemia, and LVH. Serum HDL cholesterol level showed a significant decreasing trend of mean values in parallel with GFR reduction. The prevalence of hypercholesterolemia, smoking, and obesity, as well as the mean values of BMI, showed significant intergroup variations, without a continuing trend though related to GFR values. The prev- 
alences of male gender, low HDL, as well as the mean values of diastolic pressure, did not show any significant intergroup variations.

Anemia, proteinuria, and hypoalbuminemia showed a significant rising prevalence trends, inversely dependent upon the degree of reduction of glomerular filtration, i.e. the prevalence of the above variables increased in parallel with the decline of renal function. The levels of hematocrit and serum albumins showed a positive correlation with decreasing GFR, i.e. a significant decrease dependent upon the decreasing renal function. The number of leukocytes in the peripheral blood smear and level of serum fibrinogen did not demonstrate any significant intergroup variations.

\section{Discussion}

Risk factor burden, for both traditional and non-traditional factors, is significantly higher among the patients with chronic kidney disease compared to the general population. However, this burden varies significantly with patient characteristics, including the degree of renal dysfunction and cause of renal disease. Even after correction for the factors of gender, age, race, elevated blood pressure, cardiovascular disease, diabetes, and other demographic characteristics, a relatively strong association was still present between the total burden with cardiovascular risk factors and GFR lower than $60 \mathrm{ml} / \mathrm{min} / 1.73 \mathrm{~m}^{2}[4,5,9,10]$.

Within the Modification of Diet in Renal Disease (MDRD) study, Sarnak et al. [11] found out that traditional risk factors were highly prevalent in hronic kidney disease and that their prevalence varied based on the level of renal

Table 2 Cardiovascular risk factors

\begin{tabular}{|c|c|c|c|c|}
\hline & $\begin{array}{l}\text { total number of } \\
\text { examinees } \\
205\end{array}$ & $\begin{array}{c}>60 \\
\mathrm{ml} / \mathrm{min} \\
60\end{array}$ & $\begin{array}{l}30-59 \\
\mathrm{ml} / \mathrm{min} \\
86\end{array}$ & $\begin{array}{l}15-29 \\
\mathrm{ml} / \mathrm{min} \\
59\end{array}$ \\
\hline \multicolumn{5}{|l|}{ Traditional risk factors } \\
\hline Age $*+$ & $55.1 \pm 4.9$ & $52.3 \pm 7.7$ & $59.7 \pm 8.9$ & $63.0 \pm 4.5$ \\
\hline gender (male) $*_{\mathrm{o}}$ & $48.8 \%(100 / 205)$ & $51.7 \%(31 / 60)$ & $47.7 \%(41 / 86)$ & $47.5 \%(28 / 59)$ \\
\hline hypertension $\% *+$ & $65.4 \%(134 / 205)$ & $46.7 \%(28 / 60)$ & $67.4 \%(58 / 86)$ & $81.4 \%(48 / 59)$ \\
\hline systolic blood pressure $\mathrm{mmHg} *_{+}$ & $139 \pm 12.6$ & $135 \pm 11.9$ & $143 \pm 15.3$ & $149 \pm 13.8$ \\
\hline diastolic blood pressure $\mathrm{mmHg} *_{\mathrm{o}}$ & $85 \pm 4.4$ & $84 \pm 3.9$ & $86 \pm 9.1$ & $87 \pm 7.1$ \\
\hline obesity $\% * \pm$ & $27.3 \%(56 / 205)$ & $20.0 \%(12 / 60)$ & $31.4 \%(27 / 86)$ & $28.8 \%(17 / 59)$ \\
\hline $\mathrm{BMI}\left(\mathrm{kg} / \mathrm{m}^{2}\right) * \pm$ & $28.0 \pm 2.5$ & $26.8 \pm 1.8$ & $29.4 \pm 2.2$ & $27.9 \pm 3.4$ \\
\hline glycemia mmol/1 *+ & $6.33 \pm 0.74$ & $6.08 \pm 0.52$ & $6.54 \pm 1.13$ & $7.11 \pm 0.96$ \\
\hline diabetes $\% *+$ & $18.5 \%(38 / 205)$ & $15.0 \%(9 / 60)$ & $17.4 \%(15 / 86)$ & $23.7 \%(14 / 59)$ \\
\hline total cholesterol mmol/l $*_{+}$ & $5.82 \pm 0.81$ & $5.53 \pm 1.20$ & $5.71 \pm 0.77$ & $6.26 \pm 1.35$ \\
\hline hypercholesterolemia $\% * \pm$ & $24.9 \%(51 / 205)$ & $18.3 \%(11 / 60)$ & $29.1 \%(25 / 86)$ & $25.4 \%(15 / 59)$ \\
\hline HDL mmol/l $*_{-}$ & $1.25 \pm 0.56$ & $1.32 \pm 0.47$ & $1.15 \pm 0.30$ & $1.00 \pm 0.34$ \\
\hline low HDL $\% *_{\mathrm{o}}$ & $6.3 \%(13 / 205)$ & $6.7 \%(4 / 60)$ & $5.8 \%(5 / 86)$ & $6.7 \%(4 / 59)$ \\
\hline triglycerides mmol/l *+ & $2.18 \pm 1.13$ & $1.19 \pm 0.60$ & $1.90 \pm 0.72$ & $2.94 \pm 0.88$ \\
\hline hypertriglyceridemia \% *+ & $24.4 \%(50 / 205)$ & $18.3 \%(11 / 60)$ & $24.4 \%(21 / 86)$ & $30.5 \%(18 / 59)$ \\
\hline hypertrophy LV \% *+ & $22.9 \%(47 / 205)$ & $18.3 \%(11 / 60)$ & $22.1 \%(19 / 86)$ & $28.8 \%(17 / 59)$ \\
\hline smoking $\% *_{ \pm}$ & $24.9 \%(51 / 205)$ & $31.7 \%(19 / 60)$ & $20.9 \%(18 / 86)$ & $23.7 \%(14 / 59)$ \\
\hline $\begin{array}{ll}\text { Legend: } & *_{+}-\text {positive trend } \\
& *_{-}-\text {negative trend } \\
& *_{ \pm}-\text {inter-group variation } \\
& *_{0}-\text { without trend and wi }\end{array}$ & a continuous trend & & & \\
\hline
\end{tabular}

Table 3 Cardiovascular risk factors II

\begin{tabular}{|c|c|c|c|c|}
\hline & $\begin{array}{l}\text { total number of the } \\
\text { examinees } \\
205\end{array}$ & $\begin{array}{c}>60 \\
\mathrm{ml} / \mathrm{min} \\
60\end{array}$ & $\begin{array}{l}30-59 \\
\mathrm{ml} / \mathrm{min} \\
86\end{array}$ & $\begin{array}{l}15-29 \\
\mathrm{ml} / \mathrm{min} \\
59\end{array}$ \\
\hline \multicolumn{5}{|l|}{ Non-tradicional risk factors } \\
\hline proteinuria $\% *+$ & $20.0 \%(41 / 205)$ & $11.3 \% \quad(8 / 60)$ & $17.4 \%(15 / 86)$ & $30.5 \%(18 / 59)$ \\
\hline microalbuminuria $\% *_{ \pm}$ & $28.3 \%(58 / 205)$ & $21.7 \%(13 / 60)$ & $32.6 \%(28 / 86)$ & $28.8 \%(17 / 59)$ \\
\hline anaemia $\% *_{+}$ & $25.4 \%(52 / 205)$ & $10.0 \%(6 / 60)$ & $25.6 \%(22 / 86)$ & $40.7 \%(24 / 59)$ \\
\hline hematocrit $\% *_{-}$ & $38 \pm 3.7$ & $42 \pm 5.6$ & $39 \pm 4.3$ & $33 \pm 2.5$ \\
\hline leukocytes $10^{9} / 1 *_{0}$ & $6.20 \pm 0.89$ & $6.17 \pm 0.93$ & $5.98 \pm 1.05$ & $6.24 \pm 1.44$ \\
\hline $\mathrm{S}-$ albumin $\mathrm{g} / \mathrm{l} *_{-}$ & $39.0 \pm 7.7$ & $40.9 \pm 5.8$ & $38.7 \pm 6.6$ & $37.2 \pm 4.4$ \\
\hline $\mathrm{S}-$ albumin $<3.5 \mathrm{~g} / 1 \% *_{+}$ & $7.8 \%(16 / 205)$ & $5.0 \%(3 / 60)$ & $5.8 \%(5 / 86)$ & $13.5 \%(8 / 59)$ \\
\hline $\mathrm{S}$ - fibrinogen $\mathrm{g} / \mathrm{l} *_{\mathrm{o}}$ & $3.15 \pm 0.54$ & $3.16 \pm 0.27$ & $3.03 \pm 0.63$ & $3.22 \pm 0.48$ \\
\hline $\begin{array}{lll}\text { Legend: } & *_{+}-\text {positive trend } \\
& *_{-}-\text {negative trend } \\
& *_{ \pm}-\text {inter-group val } \\
& *_{0}-\text { without trend }\end{array}$ & $\begin{array}{l}\text { ut a continuous trend } \\
\text { ter-group variations }\end{array}$ & & & \\
\hline
\end{tabular}


function, that GFR was inversely correlated with blood pressure level and positively correlated with serum HDL cholesterol level, while there were no associations with LDL cholesterol. In our examinees, systolic blood pressure and serum total cholesterol and triglyceride levels rose in parallel with declining GFR. Diastolic blood pressure was without any significant variations related to GFR alterations. There were $65.4 \%$ hypertensive individuals among the examinees, with an observed growing trend with decreasing GFR.

Jingers et al. [12] in their prospective study that lasted over 10 years observed an abnormally high incidence of atherosclerotic cardiovascular complications in pre-dialysis patients with CKD in all age groups and in both genders; their total incidence was almost three times higher than that in the general population. Smoking, poor blood pressure control, dyslipidemia with low serum HDL cholesterol, as well as higher degrees of hyperfibrinogenemia and hyperhomocysteinemia were present in CKD patients in whom atherosclerotic cardiovascular complications developed. The same factors favoring atherogenesis in the general population, such as hypertension, smoking or dyslipidemia, were present in CKD patients, but with potentiated effects, so that the incidence and severity of these disorders were higher in uremic patients. Among our examinees, there were $24.9 \%(51 / 205)$ smokers. Smoking is a very important, independent risk factor. Atherogenic effects of smoking in uremic patients are particularly striking due to increased free radical production and consequential lipid peroxidation, nevertheless increased in uremic patients [13].

In the reports by Foley et al. [1,5], individuals with renal failure were older, male, diabetic, with elevated blood pressure, smokers, and physically inactive. Hypertension is in CKD the principal risk factor for cardiovascular atherosclerotic events (especially a high systolic blood pressure). Our examinees were $55.1 \pm 4.9$ years old on average, being older with declining GFR values. Male gender was more prevalent, with $48.8 \%$ (100/205), and the ratio did not change with the progression of chronic renal failure. The average prevalence of diabetes was $18.5 \%$ (38/205), with average serum glucose $6.33 \pm 0.74 \mathrm{mmol} / \mathrm{l}$. The prevalence of diabetes in group $\mathrm{C}$, with lowest GFR values, was $23.7 \%$ (14/59). LVH was present in $22.9 \%$ (47/205), according to the echocardiographic parameters, with an incresing prevalence in CKD patients with progressively lower GFR values.

It is well known that lipid parameters are markedly altered in CKD patients compared to the general population, but the changes are more intense in patients with cardiovascular events $[3,10,12]$. Uremic dyslipidemia, i.e. low HDL cholesterol values, is the major and independent cardiovascular risk factor that occurs early during the course of chronic renal failure. Jungers et al. [12] showed that total and LDL serum cholesterol, apoB and triglyceride levels were significantly higher, while HDL cholesterol was lower, in the group of kidney patients with cardiovascular accidents compared to those without accidents. HDL cholesterol alterations in our examinees were very interesting. Expressed in absolute values, low HDL cholesterol was seen in $6.3 \%(13 / 205)$ of the examinees, and the average serum value of $\mathrm{HDL}$ cholesterol was $1.25 \pm 0.56$ $\mathrm{mmol} / \mathrm{l}$, as described in several other studies as well $[11,14]$. The mean values of serum HDL cholesterol demonstrated a significant declining trend in parallel with declining GFRs, but viewed through the prevalence of patients with low HDL cholesterol values, this risk factor did not demonstrate any significant intergroup differences. The total prevalence of hypercholesterolemia was $24.9 \%$ (51/205), being significantly higher in groups B and C compared to group $\mathrm{A}$, with the average serum cholesterol value of $5.82 \pm 0.81 \mathrm{mmol} / \mathrm{l}$. Increased triglyceride levels were encountered in $24.4 \%$ (50/205), with an average serum triglyceride value of $2.18 \pm 1.13 \mathrm{mmol} / \mathrm{l}$. Hypertriglyceridemia was most prevalent in group $\mathrm{C}$, with $30.5 \%$ (18/59).

McDonald et al. [15,16] reported a very high rate of pathological albuminuria among the members of a small community of Aboriginal people, the ethnic group with a high incidence of terminal renal failure. Their high levels of albuminuria were associated with low levels of estimated glomerular filtration rate. Albuminuria was also accompanied by increased BMI, elevated blood pressure, elevated $\mathrm{HbA} 1$ levels and diabetes. The total proportion of our patients with proteinuria was $20.0 \%$ (41/205), with the prevalences of proteinuria and serum hypoalbuminemia on the rise with the progression of chronic renal failure, and inversely dependent upon declining GFR values.

The issues of obesity and chronic renal failure have been investigated in numerous studies, attempting to prove the cause and effect relationship between a rising BMI and declining GFR [17]. In this study, there were $27.3 \%(56 / 205)$ obese examinees, with the average BMI of $28.0 \pm 2.5 \mathrm{~kg} / \mathrm{m}^{2}$. Obesity and mean BMI values showed significant intergroup variations and were without any continuing trend related to declining GFR.

The levels of hematocrit and prevalence of anemia in our examinees showed a positive correlation with declining GFR, i.e. a significant declining trend depending upon the declining renal function. The serum level of fibrinogen did now show any significant intergroup variations. In contrast, in the studies by Jungers et al. [12] and Muntner et al. [9] the serum level of fibrinogen was conspicuously higher in CKD patients compared to the healthy individuals, and significantly higher in CKD patients with cardiovascular events compared to the healthy individuals.

The number of leukocytes in the peripheral blood smear did not show any significant intergroup variations. Some studies have reported that leukocytes behave like non-traditional risk factors and as such, they are elevated in CKD [9, 18].

\section{Conclusion}

In pre-dialysis CKD patients, a high prevalence of the examined traditional and non-traditional cardiovascular risk factors was established. The cardiovascular risk progressively rises with declining GFR values, and the risk is significantly elavated already in the initial stages of chronic renal failure. 


\section{References}

1. Foley RN, Murray AM, Li S, Herzog CA, McBean AM, Eggers PW, Collins AJ. Chronic Kidney Disease and the Risk for Cardiovascular Disease, Renal Replacement, and Death in the United States Medicare Population, 1998 to 1999. J Am Soc Nephrol 2005; 16:489-495.

2. Weiner DE, Tabatabai S, Tighiouart H, Elsayed E, Bansai N, Griffith J, Salem DN, Levey AS, Sarnak MJ. Cardiovascular outcomes and all-cause mortality: exploring the interaction between chronic kidney disease and cardiovascular disease. Am J Kidney Dis 2006; 48(3):392-401.

3. Ruilope LM, Kjeldsen SE, de la Sierra A, Mancia G, Ruggenenti P, Stergiou GS, Bakris GL, Giles TD. The kidney and cardiovascular risk - implications for management: a consensus statement from the European Society of Hypertension. Blood Press 2007; 16(2): 72-79.

4. Levey AS, Coresh J. Chronic kidney disease. Lancet 2012; 14;379 (9811):165-180

5. Foley RN, Wang C, Collins AJ. Cardiovascular Risk Factor Profiles and Kidney Function Stage in the US General Population: The NHANES III Study. Mayo Clin Proc 2005; 80:1270-1277.

6. Best PJM, Holmes Jr DR. Chronic kidney disease as a cardiovascular risk factor. Am Heart J March 2003; 145(3): 383-386.

7. Weiner DE, Tighiouart H, Elsayed EF et al. The Framingham Predictive Instrument in Chronic Kidney Disease. J Am Coll Cardiol 2007; 50(3):217-224.

8. Gansevoort RT, Correa-Rotter R, Hemmelgarn BR et al. Chronic kidney disease and cardiovascular risk: epidemiology, mechanisms, and prevention. Lancet 2013; 382(9889):339-352.
9. Muntner P, He J, Astor BC, Folsom AR, Coresh J. Traditional and Nontraditional Risk Factors Predict Coronary Heart Disease in Chronic Kidney Disease: Results from the Atherosclerosis Risk in Communities Study. J Am Soc Nephrol 2005; 16:529-538.

10. Ruiz-Hurtado G, Sarafidis P, Fernández-Alfonso MS, Waeber B, Ruilope LM. Global cardiovascular protection in chronic kidney disease. Nat. Rev. Cardiol. 2016;13:603-608.

11. Sarnak MJ, Coronado BE, Greene T, Wang SR, Kusek JW, Beck GJ, Levey AS. Cardiovascular disease risk factors in chronic renal insufficiency. Clin Nephrol 2002; 57(5):327-335.

12. Jungers P, Massy ZA, Nguyen Khoa T, Fumeron C, Labrunie M, Lacour B, Descamps-Latscha B, Man NK. Incidence and risk factors of atherosclerotic cardiovascular accidents in predialysis chronic renal failure patients: a prospective study. Nephrol Dial Transplant 1997; 12:2597-2602.

13. Hallan SI, Orth SR. Smoking is a risk factor in the progression to kidney failure. Kidney Int 2011; 80:516-523.

14. Parikh NI, Hwang SJ, Larson MG, Meigs JB, Levy D, Fox CS Cardiovascular Disease Risk Factors in Chronic Kidney Disease: Overall Burden and Rates of Treatment and Control. Arch Intern Med 2006; 166:1884-1891.

15. McDonald SP, Maguire GP, Hoy WE. Renal function and cardiovascular risk markers in a remote Australian Aboriginal community. Nephrol Dial Transplant 2003; 18:1555-1561.

16. Hoy WE, Mott SA, McDonald SP. An expanded nationwide view of chronic kidney disease in Aboriginal Australians. Nephrology 2016; 21(11):916-922.

17. Stenvinkel P, Zoccali C, Ikizler TA. Obesity in CKD - what should nephrologists know? J Am Soc Nephrol 2013; 24 (11):1727-1736.

18. Sun J, Axelsson J, Machowska A, et al. Biomarkers of Cardiovascular Disease and Mortality Risk in Patients with Advanced CKD. CJASN July 07, 2016 11): (7)1163-1172. 